\title{
DAMPAK PROGRAM IbPE BAGI UKM GULA KELAPA DI KABUPATEN BANYUMAS PROVINSI JAWA TENGAH
}

\author{
Suliyanto \\ Dosen Fakultas Ekonomi dan Bisnis Universitas Jenderal Soedirman
}

\author{
Weni Novandari
}

Dosen Fakultas Ekonomi dan Bisnis Universitas Jenderal Soedirman

Mustaufik

Dosen Fakultas Pertanian Universitas Jenderal Soedirman

\begin{abstract}
IbPE program aims to increase the export growth of SMEs Coconat-Sugar through increased production, increased sales, improved quality of coconut sugar accompanied by increased management of activity. This program was conducted by the method of training, mentoring and enhance production facilities according with a target of SMEs Ngudi Lestari and SMEs Lestari Jaya in Kalisalak Village, Kebasen sub-district, Banyumas district during the years 2014-2016. Based on the differences analysis in performance of SMEs was concluded there is an increased performance of SMEs based on the indicators of the amount of production, turnover, export, labor, and there is an increase in production management, human resource management, financial management.
\end{abstract}

Keyword : Coconut Sugar, Small Medium Enterprises, IbPE

\section{ABSTRAK}

Program BPE bertujuan untuk meningkatkan pertumbuhan ekspor UKM Coconat-Sugar melalui peningkatan produksi, peningkatan penjualan, peningkatan kualitas gula kelapa disertai dengan peningkatan manajemen kegiatan. Program ini dilakukan dengan metode pelatihan, pendampingan dan meningkatkan fasilitas produksi sesuai dengan target UKM Ngudi Lestari dan UKM Lestari Jaya di Kalisalak Desa, Kecamatan Kebasen, Kabupaten Banyumas selama tahun 2014-2016. Berdasarkan analisis perbedaan kinerja UKM dapat disimpulkan ada peningkatan kinerja UKM berdasarkan indikator dari jumlah produksi, omset, ekspor, tenaga kerja, dan terdapat juga peningkatan pada manajemen produksi, manajemen sumber daya manusia, dan manajemen keuangan.

Kata kunci : Gula Kelapa, Usaha Kecil Menengah, IbPE

\section{PENDAHULUAN}

Program Iptek bagi Produk Ekspor (IbPE) Gula Kelapa di Kabupaten Banyumas Provinsi Jawa Tengah merupakan program pengabdian kepada masyarakat yang merupakan kerja sama antara Direktorat Penelitian dan Pengabdian Kepada Masyarakat Kemenristek Dikti dengan Lembaga Penelitian dan Pengabdian kepada Masyarakat Universitas Jenderal Soedirman. Gula kelapa sangat strategis untuk dikembangkan karena bahan baku yang berlimpah dan murah, teknologi yang digunakan untuk membuat gula kelapa juga termasuk low cost and low tech atau tidak membutuhkan biaya dan teknologi yang tinggi (Mustaufik dan Pepita, 2009). Areal kelapa yang mencapai 3,74 juta ha atau 27\% dari total areal perkebunan di Indonesia (Mahmud, 2008), hal ini menjadikan Indonesia sebagai negara penghasil gula kelapa terbesar di dunia (Suliyanto 2013).

Program ini bertujuan untuk memacu pertumbuhan ekspor UKM Gula Kelapa melalui pertumbuhan jumlah produksi, pertumbuhan penjualan, peningkatan kualitas gula kelapa disertai peningkatan manajemen usaha. Beberapa permasalahan yang diselesaikan dalam program IbPE 
adalah masalah yang dihadapi oleh UKM Gula Kelapa yaitu masalah kualitas dan kuantitas produksi, masalah pemasaran, dan masalah manajemen (Suliyanto, et al., 2013). Untuk mengukur tingkat keberhasilan program IbPE ini maka diperlukan evaluasi tentang dampak program IbPE bagi mitra dilihat dari berbagai indikator, yaitu: jumlah produksi, omset per bulan, penyerapan tenaga kerja, dan dari manajemen.

\section{METODE PELAKSANAAN}

Metode pelaksanaan Program Iptek bagi Produk Ekspor (IbPE) Gula Kelapa di Banyumas Provinsi Jawa Tengah hal ini karena Kabupaten Banyumas merupakan sentra gula kelapa di Indonesia (Suliyanto dkk, 2012). Program IbPE ini dilaksanakan dengan berbagai kegiatan dengan sasaran dua UKM Gula Kelapa yaitu UD Ngudi Lestari dan UD Lestari Jaya yang beralamat di Desa Kalisalak, Kecamatan Kebasen, Kabupaten Banyumas. Kegiatan ini dilaksanakan selama tiga tahun yaitu dari tahun 2014-2016. Beberapa kegiatan yang dilaksanakan selama periode tersebut adalah sebagai berikut :

Tahun ke-1: Peningkatan kontrol kualitas (quality control) bahan baku dan proses produksi; Peningkatan kualitas produk; Penyediaan fasilitas alat produksi berupa cetakan gula standar ekspor untuk memenuhi permintaan pasar luar negeri dan Pendampingan dan perbaikan manajemen usaha mitra. Tahun ke-2: Perbaikan desain atau layout ruang produksi; Perbaikan dan peningkatan kebersihan (higienitas) produk; Penyediaan fasilitas genset untuk menjaga stabilitas produksi, Pelatihan untuk peningkatan kemampuan dan jumlah SDM dalam melakukan diversifikasi produk. Tahun ke-3: Perluasan pasar produk; Pelatihan dan pendampingan proses pengajuan sertifikasi SNI; Penyediaan instalansi pembuangan limbah, Pelatihan dan pendampingan proses sertifikasi mutu organik dan Peningkatan kualitas lingkungan melalui pengolahan limbah.

\section{HASIL KEGIATAN}

Untuk melihat dampak program Program Iptek bagi Produk Ekspor (IbPE) Gula Kelapa di Banyumas Provinsi Jawa Tengah dilakukan analisis perkembangan jumlah produksi, omset penjualan, jumlah ekspor, penyerapan tenaga kerja, perkembangan manajemen dan perkembangan jumlah fasilitas produksi yang dimiliki oleh UKM Gula Kelapa yang menjadi sasaran kegiatan. Perkembangan UKM Gula Kelapa sebelum dan sesudah adanya program IbPE dari beberapa indikator adalah sebagai berikut.

Jumlah Produksi

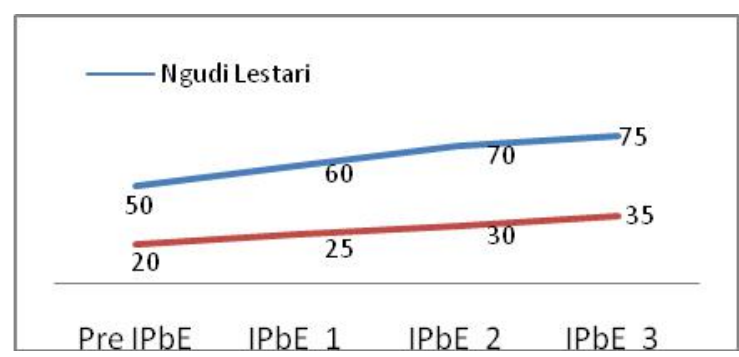

Gambar 1: Perkembangan Jumlah Produksi per Bulan UKM Ngudi Lestari dan UKM Lestari Jaya (dalam ton/bulan)

Berdasarkan gambar di atas, dapat digambarkan perkembangan jumlah produksi pada UKM Gula Kelapa. Garis berwarna biru menunjukkan perkembangan UKM Ngudi Lestari dan garis berwarna merah menunjukkan perkembangan jumlah produksi UKM Lestari Jaya. Jumlah sebelum adanya program IbPE dapat digambarkan masing-masing sebanyak 50 ton per bulan dan 20 ton per bulan.

Program IbPE menunjukkan hasil yang baik pada UKM Gula Kelapa di Kabupaten Banyumas, salah satu indikator ialah adanya peningkatan jumlah produksi dari sebelum program IbPE dan setelah adanya program IbPE. Peningkatan tersebut pada UKM Ngudi Lestari dan UKM Lestari Jaya masing-masing sebanyak 10 ton per bulan dan 5 ton per bulan. Awalnya sebelum 
adanya program IbPE, UKM Ngudi Lestari memiliki jumlah produksi 50 ton per bulan setelah adanya program IbPE mengalami peningkatan jumlah produksi menjadi 60 ton per bulan. Pada UKM Lestari Jaya sebelum adanya program IbPE memiliki jumlah produksi sebesar 20 ton perbulan, setelah adanya program IbPE mengalami peningkatan jumlah produksi menjadi 25 ton per bulan.

Peningkatan jumlah produksi terus meningkat sampai dengan tahun ketiga adanya program IbPE. Pada tahun ketiga UKM Ngudi Lestari mengalami peningkatan jumlah produksi mencapai 50 persen dibandingkan jumlah produksi sebelum adanya program IbPE menjadi 75 ton per bulan. Di sisi lain, UKM Lestari Jaya mengalami peningkatan jumlah produksi mencapai 75 persen dibandingkan jumlah produksi sebelum adanya program IbPE, manjadi 35 ton per bulan pada tahun ketiga adanya program IbPE.

\section{Omzet Per Bulan}

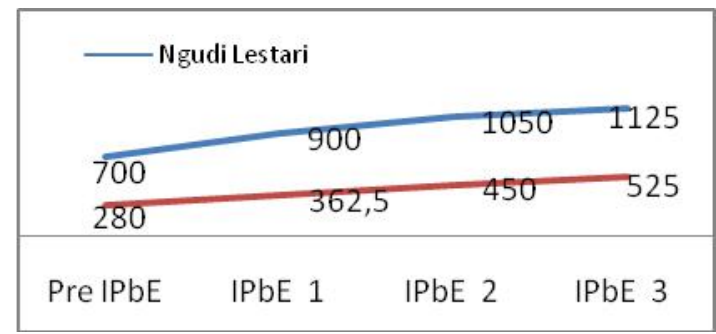

Gambar 2: Perkembangan Omset per Bulan UKM Ngudi Lestari dan UKM Lestari Jaya (dalam juta/bulan)

Berdasarkan gambar di atas dapat dilihat peningkatan omzet per bulan pada masing-masing UKM Gula Kelapa. Garis biru menunjukkan peningkatan UKM Ngudi Lestari sedangkan garis merah menggambarkan peningkatan pada UKM Lestari Jaya. Pada UKM Ngudi Lestari, rata-rata omzet per bulan sebesar 700 juta. Dibandingkan dengan setelah adanya program IbPE telah mengalami peningkatan yang signifikan mencapai 900 juta per bulan pada tahun pertama adanya pogram IbPE. Peningkatan rata-rata omzet per bulan sebesar 200 juta atau 29 persen pada tahun pertama program IbPE. Pada tahun kedua dan ketiga tetap mengalami peningkatan, hingga pada tahun ketiga adanya program IbPE rata-rata omzet per bulan mencapai 1.125 juta atau menembus angka 1,1 miliar perbulan. Hasil yang baik menunjukkan tercapainya pelaksanaan perberdayaan pengembangan UKM yang baik.

UKM Lestari Jaya pada sebelum adanya program IbPE menunjukkan rata-rata omzet sebesar 280 juta per bulan. Rata-rata omzet per bulan setelah adanya program IbPE mengalami peningkatan mencapai 362,5 juta per bulan pada tahun pertama program IbPE. Dibandingkan dengan omzet rata-rata per bulan sebelum program IbPE, pada tahun pertama telah mengalami peningkatan mencapai lebih dari 29 persen. Lebih dari itu, peningkatan ini tetap berlangsung sampai dengan tahun ketiga adanya program IbPE. Pada tahun ketiga program IbPE, UKM Lestari Jaya memiliki rata-rata omzet per bulan menembus angka 525 juta. Omzet dapat menggambarkan efektivitas produksi dan penjualan dengan adanya program IbPE, dengan tujuan akhir adalah peningkatan ekspor pada masing-masing UKM Gula Kelapa.

\section{Jumlah Ekspor}

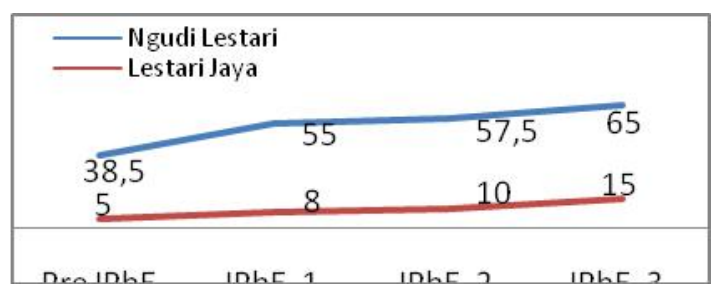

Gambar 3: Perkembangan Jumlah Ekspor per Bulan UKM Ngudi Lestari dan UKM Lestari Jaya (dalam ton/bulan) 
Jumlah ekspor pada masing-masing UKM Gula Kelapa diproyeksikan akan meningkat dengan adanya program IbPE. Hal tersebut dibuktikan dengan gambar di atas yang menunjukkan peningkatan jumlah ekspor pada masing-maisng UKM Gula Kelapa. Keterangan garis berwarna biru menunjukkan peningkatan pada UKM Ngudi Lestari, sedangkan garis berwarna merah menunjukkan peningkatan jumlah ekspor pada UKM Lestari Jaya.

Berdasarkan gambar tersebut, dapat dilihat pada UKM Ngudi Lestari rata-rata kapasitas ekspor sebelum adanya program IbPE sebesar 38,5 ton per bulan. Setelah adanya program IbPE, menunjukkan peningkatan jumlah produksi sebesar lebih dari 42 persen dimana menembus angka 55 ton per bulan pada tahun pertama program IbPE. Hingga pada tahun ketiga, UKM Ngudi Lestari memiliki rata-rata jumlah ekspor mencapai 65 ton per bulan. Di sisi lain, pada UKM Lestari Jaya memiliki rata-rata jumlah ekspor sebesar 5 ton per bulan saat sebelum adanya program IbPE. Setelah adanya program IbPE, dapat dilihat bahwa mengalami peningkatan mencapai 60 persen pada tahun pertama program IbPE dimana sebesar 8 ton per bulan. Peningkatan yang signifikan terjadi pada tahun ketiga pasca adanya program IbPE yaitu mencapai 15 ton per bulan. Hasil tersebut menunjukkan peningkatan sebesar 200 persen dibandingkan sebelum adanya program IbPE.

Jumlah Tenaga Kerja

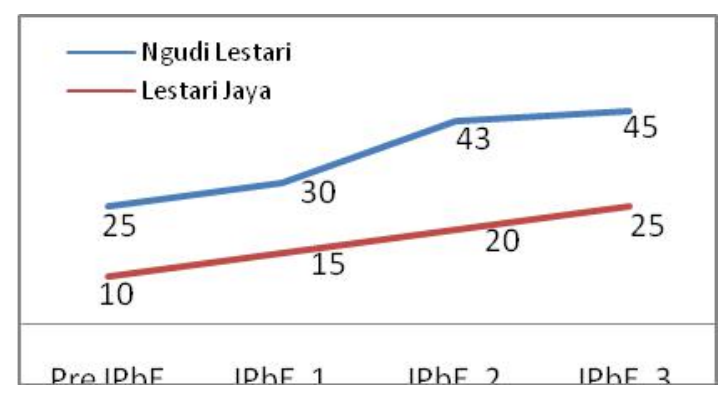

Gambar 4: Perkembangan Jumlah Tenaga Kerja UKM Ngudi Lestari dan UKM Lestari Jaya

Ketersediaan tenaga kerja pada UKM Gula Kelapa mengalami peningkatan seiring dengan peningkatan produksi dari sebelum adanya program IbPE dibandingkan dengan setelah program IbPE. Garis biru menunjukkan perkembangan UKM Ngudi Lesatri sedangkan garis berwarna merah menunjukkan perkembangan UKM Lestari Jaya. Pada saat sebelum adanya program IbPE, UKM Ngudi Lestari memiliki jumlah tenaga kerja sebanyak 25 orang. Terdapat kenaikan jumlah tenaga kerja pada tahun pertama program IbPE menjadi 30 orang. Hal ini diperlukan untuk memenuhi kebutuhan tenaga kerja seiring dengan peningkatan jumlah produksi dan ekspor.

Hal serupa terjadi pada UKM Lestari Jaya dengan peningkatan jumlah tenaga kerja pada tahun pertama program IbPE sebanyak 15 orang dibandingkan dengan sebelum adanya program IbPE yaitu sejumlah 10 orang tenaga kerja. Pada tahun ketiga program IbPE, UKM Lestari Jaya memiliki jumlah tenaga kerja sebanyak 25 orang, hal ini menunjukkan peningkatan yang signifikan sebesar 150 persen dibandingkan dengan jumlah tenaga kerja sebelum adanya program IbPE.

\section{Manajemen Usaha}

Terdapat tiga aspek dalam UKM Gula Kelapa guna menyokong sistem tata kelola kegiatan, aspek-aspek tersebut meliputi manajemen SDM, manajemen keuangan, dan manajemen produksi. Manajemen SDM pada masing masing UKM Gula Kelapa setelah program IbPE semakin meningkat. Secara umum pada tahun ketiga program IbPE, manajemen SDM masingmasing UKM Gula Kelapa telah memiliki jaminan sosial untuk para karyawan, para karyawan telah memahami benar untuk menjaga kebersihan dan higienitas dalam proses produksi yang diwujudkan dengan selalu menggunakan pakaian standard kerja yang dilengkapi dengan penutup kepala beserta masker dan sarung tangan. Lebih lanjut, pada UKM Ngudi Lestari dan UKM 
Lestari Jaya telah mengalami peningkatan dalam aspek manajemen SDM yaitu dengan mengetahui tata cara pengurusan Standar Nasional Indonesia (SNI) serta telah memiliki pengetahuan pengurusan sertifikasi organik.

Manajemen keuangan pada masing masing UKM Gula Kelapa secara umum belum memiliki catatan pembukuan keuangan yang baik sebelum adanya program IbPE. Setelah adanya program IbPE, terdapat peningkatan dengan sudah memiliki pencatatan pembukuan keuangan yang jauh lebih baik, sehingga dapat menyokong continuous improvement kegiatan usaha.

Secara umum, manajemen produksi pada UKM Ngudi Lestari dan UKM Lestari Jaya setelah adanya program IbPE telah memiliki ruang produksi yang higienis. Masing-masing UKM telah memiliki layout ruang produksi yang lebih optimal dibandingkan sebelum adanya program IbPE.Bahan baku pembuatan gula kelapa telah mengalami peningkatan dengan digunakannya bahan baku nira dengan kandungan air mineral. Lebih lanjut, penggunaan laru Natrium Bisulfit menurun dengan drastis. Pada saat sebelum program IbPE masih banyak menggunakan laru Natrium Bisulfit, sedangkan setelah adanya program IbPE penggunaan laru menurun hingga 50 persen. Kandungan kotoran menurun sampai dengan 0 persen setelah adanya program IbPE. Proses produksi membutuhkan pasokan listrik dari PLN, setelah adanya program IbPE ketergantungan pada listrik dari PLN berkurang serta pembuangan limbah telah melalui tahap penyaringan sehingga lebih ramah lingkungan.

\section{Fasilitas Produksi}

Berbagai peningkatan yang ada ditunjang dengan fasilitas yang semakin lengkap. Program IbPE pada UKM Gula Kelapa memberikan saran dan evaluasi bagaimana cara untuk memaksimalkan kinerja. Salah satu cara dengan penambahan fasilitas pada masing-masing UKM yaitu penambahan alat refractometer, alat penyaringan nira dimodifikasi, cetakan gula berbagai ukuran, alat blengker alumunium, wajan,mixer, alat pengering cetakan dimodifikasi, genset listrik, alat kusting dan sabit, serta pakaian kerja untuk para karyawan. Selain itu, pada masing-masing UKM telah memproses adanya merek produk beserta Standar Nasional Indonesia (SNI). Berbagai peningkatan bertujuan untuk meningkatkan daya saing UKM Gula Kelapa agar dapat meningkatkan jumlah ekspor, keberlangsungan kegiatan usaha, serta kesejeahteraan para karyawan yang tidak lain adalah warga sekitar.

\section{KESIMPULAN}

Berdasarkan hasil evaluasi tentang pelaksanaan program IbPE tahun pertama, dapat diperoleh kesimpulan sebagai berikut ini:

1. Program IbPE dapat meningkatkan jumlah produksi per bulan sebesar $50 \%$ pada UKM Ngudi Lestari dan $75 \%$ pada UKM Lestari Jaya.

2. Program IbPE dapat meningkatkan omset penjualan per bulan sebesar $61 \%$ pada UKM Ngudi Lestari dan $87 \%$ pada UKM Lestari Jaya.

3. Program IbPE dapat meningkatkan jumlah ekspor per bulan sebesar $69 \%$ pada UKM Ngudi Lestari dan 200\% pada UKM Lestari Jaya.

4. Program IbPE dapat meningkatkan jumlah tenaga kerja sebesar $80 \%$ pada UKM Ngudi Lestari dan $150 \%$ pada UKM Lestari Jaya.

5. Program IbPE dapat meningkatkan manajemen usaha yaitu manajemen SDM, Manajemen Keuangan dan manajemen produksi pada UKM Ngudi Lestari dan UKM Lestari Jaya.

6. Program IbPE dapat meningkatkan usaha pada UKM Ngudi Lestari dan UKM Lestari Jaya yaitu cetakan gula, mixer, wajan, pongkor, saringan, blengker, sabit, kusting, genset refraktor meter dan instalansi pembuangan limbah. 


\section{DAFTAR PUSTAKA}

Suliyanto. (2013a) Financing Model for Coconut Sugar Micro Small Medium Entreprises (SMEs) In Indonesia. International Business managemen, 7(5).410-413.

Suliyanto, Suroso, A., \& Jati, D. P. (2013). Potential and Problems of Small Medium Enterprise (SMEs) Coconut-Sugar: Case Study in Banyumas Regency, Central Java Indonesia. International Journal of Business and Management, 8(3), 18-26

Mahmud, Z. (2008). Modernisasi usaha tani kelapa rakyat. Pengembangan Inovasi Pertanian, 1(4), 274-287.

Mustaufik dan Pepita Haryanti. 2009. Evaluasi Keamanan Pagan dan Penyimpangan Mutu Gula Kelapa Kristal di Kabupaten Banyumas. Laporan Penelitian Riset Strategis Nasional (Rusnas). DP2M Dikti, Jakarta.

Suliyanto, Agus Suroso, Anisur Rosyad, Ali Rokhman, Laeli Budiarti, Dian Purnomo Jati (2012). Model Pengembangan Usaha Mikro Kecil Dan Menengah (UMKM) Gula Kelapa. Laporan Penelitian tidak dipublikasi. LPPM Universitas Jenderal Soedirman. 